\title{
Effect of oxycodone patient-controlled intravenous analgesia after cesarean section: a randomized controlled study
}

This article was published in the following Dove Press journal: Journal of Pain Research

10 November 2017

Number of times this article has been viewed

Jing-jing Nie*

Shen Sun

Shao-qiang Huang*

Department of Anesthesiology, Obstetrics and Gynecology Hospital of Fudan University, Shanghai, China

*These authors contributed equally to this work
Correspondence: Shen Sun

Department of Anesthesiology, Obstetrics and Gynecology Hospital of Fudan University, Number 128, Shenyang Road, Shanghai, 200090, China

Fax +86 21 63455090

Email sunshen1980@।26.com
Background: Oxycodone is a semisynthetic $\mu$-opioid receptor agonist with a potentially good analgesic efficacy in visceral pain. This study aims to compare the efficacy of oxycodone with sufentanil patient-controlled intravenous analgesia (PCIA).

Methods: One hundred and twenty primiparas undergoing elective cesarean section were randomized into four groups by different drugs of PCIA: group S (sufentanil $100 \mu \mathrm{g}$ ), group OS1 (sufentanil $70 \mu \mathrm{g}$, oxycodone $30 \mathrm{mg}$ ), group OS2 (sufentanil $50 \mu \mathrm{g}$, oxycodone $50 \mathrm{mg}$ ), and group $\mathrm{O}$ (oxycodone $100 \mathrm{mg}$ ). Ramosetron $0.3 \mathrm{mg}$ was added to each group. In all groups, drugs were diluted to $100 \mathrm{~mL}$ and managed with a continuous infusion of $1 \mathrm{~mL} \cdot \mathrm{h}^{-1}$, a bolus dose of $2 \mathrm{~mL}$, and a lockout interval of $15 \mathrm{~min}$. The maximum dose of PCIA per hour was $10 \mathrm{~mL}$. After surgery, pain scores, PCIA doses, and side effects were compared among groups. Results: At all time points (6, 12, and $24 \mathrm{~h}$ after surgery), Numerical Rating Scale (NRS) of uterine cramping pain (NRS-U) scores in group $\mathrm{O}$ were lower than those in groups OS1 and $\mathrm{S}$ $(P<0.008)$ and NRS-U scores in groups OS2 and OS1 were lower than that in group $\mathrm{S}(P<0.008)$. NRS of moving into the sitting position (NRS-S) scores in group $\mathrm{O}$ were lower than those in the other groups $(P<0.008)$. NRS-S scores in group OS2 were lower than those in groups OS1 and $\mathrm{S}(P<0.008)$. At 12 and $24 \mathrm{~h}$ after surgery, NRS of incision pain at rest (NRS-R) scores in group $\mathrm{O}$ were lower than those in the other groups $(P<0.008)$. At all time points, NRS-R scores in group OS2 were lower than those in groups OS1 and $\mathrm{S}(P<0.008)$. The number of PCIA boluses and amount of opioid consumption in group $\mathrm{O}$ were lower than those in groups OS1 and $\mathrm{S}$ at all time points $(P<0.008)$

Conclusion: Oxycodone PCIA may be more effective than sufentanil PCIA for pain relief after cesarean section but the incidence of side effects needs further investigation.

Keywords: cesarean section, postoperative pain, oxycodone, sufentanil

\section{Introduction}

Cesarean section (CS) is often associated with significant postoperative pain, including incision pain and uterine cramping pain. Clinically, the use of high-dose oxytocin after CS to promote uterine recovery and reduce postpartum hemorrhage often leads to severe uterine cramping pain which is often ignored. ${ }^{1}$ Poor postCS pain control may interfere with ambulation, breastfeeding, and early maternal bonding with the infant. ${ }^{2}$ However, no gold standard is currently available for postCS pain management or for the treatment of uterine cramping pain. ${ }^{1}$

Sufentanil, a selective $\mu$-receptor agonist, is ideal for patient-controlled intravenous analgesia (PCIA) due to its fast onset, short duration, and strong analgesic effect, ${ }^{2}$ with a lower incidence of respiratory depression than morphine, alfentanil, and fentanyl. ${ }^{3-6}$ 
However, similar to other opioids, sufentanil may induce adverse reactions such as nausea, vomiting, dizziness, drowsiness, and respiratory depression. ${ }^{7}$ Improvement in analgesic effects is warranted, especially for uterine cramping pain. Oxycodone is a semisynthetic $\mu$-opioid receptor agonist with an additional effect on $\kappa$-receptors, ${ }^{8-10}$ which may be an important feature for antinociception in the visceral pain system. ${ }^{11}$ Oxycodone has weaker $\mu$-receptor affinity than sufentanil, which may mitigate the reaction of nausea and vomiting caused by $\mu$-receptor agonism. ${ }^{12}$

Oral oxycodone has been used widely for the treatment of postoperative pain, chronic pain, and pain due to malignant disease. ${ }^{13}$ However, the effect of intravenous oxycodone administration after CS remains unclear and previous studies did not distinguish uterine cramping pain from incision pain. ${ }^{1}$ We hypothesized that oxycodone can enhance the quality of analgesia, especially relative to visceral pain, and mitigate side effects. Our primary outcome was the quality of postoperative pain relief provided by oxycodone compared with sufentanil PCIA. The secondary outcome was side effects within $24 \mathrm{~h}$ after cesarean delivery.

\section{Methods}

This prospective, randomized, double-blind study was approved by the Medical Ethics Committee of the Obstetrics and Gynecology Hospital of Fudan University, Shanghai, China, and was registered at https://clinicaltrials.gov/ (registration number ChiCTR-IIR-16008708). It was conducted at the Department of Anesthesiology, Obstetrics and Gynecology Hospital of Fudan University, Shanghai, China, between May 2015 and January 2017. One hundred and twenty-three American Society of Anesthesiologists (ASA) physical status II healthy primiparas undergoing elective lower segment CS with spinal anesthesia were selected for the study and written informed consent was obtained from all participants. The inclusion criteria were age between 18 and 40 years and height from 150 to $175 \mathrm{~cm}$. The exclusion criteria included pregnancy complicated by hypertension, diabetes mellitus, cardiac disease or renal disease, a long history of opioid use, analgesic drug utilization within $24 \mathrm{~h}$ of CS, and chronic pain. Patients who could not use the Numerical Rating Scale (NRS) were also excluded from the study.

Patients were randomly divided into four groups according to different drugs used for PCIA after the operation: group S (sufentanil $100 \mu \mathrm{g}$ ), group OS1 (sufentanil $70 \mu \mathrm{g}$, oxycodone $30 \mathrm{mg}$ ), group OS2 (sufentanil $50 \mu \mathrm{g}$, oxycodone $50 \mathrm{mg}$ ), and group $\mathrm{O}$ (oxycodone $100 \mathrm{mg}$ ). Ramosetron 0.3 $\mathrm{mg}$ was added to each group. In all groups, the drugs were diluted to $100 \mathrm{~mL}$ and managed with a continuous infusion of $1 \mathrm{~mL} \cdot \mathrm{h}^{-1}$, a bolus dose of $2 \mathrm{~mL}$, and a lockout interval of $15 \mathrm{~min}$. The maximum dose of PCIA per hour was $10 \mathrm{~mL}$. Each patient-controlled analgesia (PCA) button push delivers sufentanil $2 \mu \mathrm{g}$ in group $\mathrm{S}$, sufentanil $1.4 \mu \mathrm{g}$ and oxycodone $0.6 \mathrm{mg}$ in group OS1, sufentanil $1 \mu \mathrm{g}$ and oxycodone $1 \mathrm{mg}$ in group OS2, and oxycodone $2 \mathrm{mg}$ in group $\mathrm{O}$. Because there are no recommendations regarding the direct conversion factor for the doses of intravenous oxycodone and fentanyl, a potency ratio of 100:1 was implemented by conversion to morphine. ${ }^{14}$ The price of sufentanil to fentanyl is $1: 10$, so we considered $1 \mathrm{mg}$ of parenteral oxycodone to be equivalent to $1 \mu \mathrm{g}$ of sufentanil. Therefore, we chose $1 \mathrm{mg} / \mathrm{mL}$ of oxycodone and $1 \mu \mathrm{g} / \mathrm{mL}$ of sufentanil for the PCIA drug protocol in this study, resulting in four groups receiving equivalent levels of analgesia.

Four sets of randomized medication codes were generated by a computer, with 30 codes in each set, which were maintained by the medication staff and follow-up manager after the results were sealed. The test drug was randomly selected by the computer half an hour before the test and was then diluted to $100 \mathrm{~mL}$ of clear liquid by the same researcher. The solution was given to the operator and connected to the analgesic pump at the end of the operation. This researcher was not involved in any procedure or in data collection.

All patients received $500 \mathrm{~mL}$ of hydroxyethyl starch solution before anesthesia administration and were placed in the supine position at a $15^{\circ}$ left lateral tilt. Electrocardiography, heart rate, blood pressure, and oxygen saturation were monitored using the S/5 Anesthesia Monitor (GE Healthcare, Helsinki, Finland). The mean values of the abovementioned parameters recorded at 3-min intervals three consecutive times served as baseline values. Combined spinal-epidural anesthesia was administered in the left lateral position at the $\mathrm{L}_{3-4}$ vertebral interspace. One percent isobaric ropivacaine $15 \mathrm{mg}(1.5 \mathrm{~mL})$ was diluted to $3 \mathrm{~mL}$ with cerebrospinal fluid and injected into the subarachnoid space over 15-30 s. Sensory and motor block levels were assessed at 3-min intervals for the first $10 \mathrm{~min}$ after spinal injection. Surgery commenced when the sensory block reached the T6 level. Patients who did not achieve this level were excluded from the study, and 1.5\% lidocaine was administered epidurally until successful anesthesia was achieved. During the operation, $20 \mathrm{U}$ of oxytocin was added to $500 \mathrm{~mL}$ of ringer's lactate solution to promote uterine contraction. Hypotension was defined as a decrease in systolic pressure to $<80 \%$ of baseline. Phenylephrine 100 $\mu \mathrm{g}$ was given when hypotension developed. Bradycardia was defined as a heart rate $<50$ beats $/ \mathrm{min}$. Atropine $0.3 \mathrm{mg}$ was administered as necessary to treat bradycardia. Flurbiprofen 
axetil $50 \mathrm{mg}$ was administered intravenously at 0 and $6 \mathrm{~h}$ postoperatively. When patients arrived at the postanesthesia care unit (PACU), they received pain control via PCIA (AM330; ACE Medical, Gyeonggi-Do, Korea). If patients complained of severe pain postoperatively (NRS $>4$ ), they could press the PCIA instead of receiving other rescue analgesics.

A blinded observer assessed NRS of incision pain at rest (NRS-R), NRS of moving into the sitting position (NRS-S), and NRS of uterine cramping pain (NRS-U), and measured cumulative PCIA doses at 6, 12, and $24 \mathrm{~h}$ after the operation (with " 0 " indicating no pain, " 5 " indicating moderate pain, and " 10 " representing the worst pain). ${ }^{10}$ To minimize subjective variations in the evaluation of NRS, the same physician (SS) explained the pain intensity scale to all patients. At each follow-up visit, detailed instructions explaining how to use the NRS were read aloud, and then the patients reported the NRS that best reflected their pain status to the same physician. The physician recorded the pain rating and patients' responses on an analgesic questionnaire. Side effects such as hypotension (systolic blood pressure $<90 \mathrm{mmHg}$ ), hypoxemia $\left(\mathrm{SpO}_{2}<90 \%\right.$ ), respiratory depression (respiratory rate $<10$ breaths per min for $>10 \mathrm{~min}$ ), nausea, vomiting, pruritus, and dizziness were also recorded at 6, 12, and $24 \mathrm{~h}$ after surgery. The Ramsay Sedation Scale was applied to assess sedation level: 1 = anxious, agitated, or restless; 2 = cooperative, oriented, and tranquil; $3=$ responds to command; $4=$ brisk response to a light glabellar tap or loud auditory stimulus; 5 = sluggish response to a light glabellar tap or loud auditory stimulus; $6=$ no response to the stimuli. ${ }^{15}$ If respiratory depression had occurred, oxygen and naloxone would have been used. Hypotension and bradycardia were treated with phenylephrine and atropine, respectively. If a patient had severe nausea or vomiting, ramosetron $0.3 \mathrm{mg}$ was injected intravenously. The primiparas were asked to rank their satisfaction according to the following scale at $24 \mathrm{~h}$ after surgery: $1=$ very unsatisfactory; $2=$ unsatisfactory; $3=$ neutral; $4=$ satisfactory; $5=$ very satisfactory. ${ }^{15}$

\section{Statistical analysis}

Basic descriptive statistics for primipara characteristics are given by the mean $\pm \mathrm{SD}$ or the median (interquartile range). The statistical analysis was performed with SPSS 24.0 for Windows (SPSS, Inc., IBM) and Graphpad Prism 7 (GraphPad Software, La Jolla, CA, USA). A repeated measures analysis of variance (ANOVA) with Bonferroni correction was used for pain scores and cumulative PCIA doses. The incidence of side effects and satisfaction scores were compared using the Pearson chi-square test with Bonferroni correction. The Bonferroni correction was determined as follows: the significance criterion for each test $=\alpha / \mathrm{c},{ }^{16}$ where $\alpha$ is our priori significance level of 0.05 for the comparisons and $\mathrm{c}$ is the number of comparisons. In our study, $\mathrm{c}=6$, so the calculated significance criterion was 0.008 .

NRS-U at 6, 12, and $24 \mathrm{~h}$ after surgery was considered the primary efficacy variable. We calculated the sample size for NRS-U using $G^{*}$ Power 3.1 software. ${ }^{17,18}$ In a preliminary trial with 30 primiparas, the SD of NRS-U after CS was 2. With a one-tailed $\alpha$ of 0.05 , to detect a difference of $\geq 1$ in NRS-U after CS, we planned to enroll 24 patients in each group to acquire the desired power of $90 \%$. After accounting for potential exclusions, we enrolled 30 patients in each group.

\section{Results}

One primipara was excluded for refusing to report pain scores and two refused to participate. The remaining 120 primiparas were enrolled after randomization (Figure 1). Demographic and obstetric characteristics were not different among the groups (Table 1).

At most time points (12 and $24 \mathrm{~h}$ ) measured, NRS-R scores in group $\mathrm{O}(1.76 \pm 0.87,1.24 \pm 0.79)$ were lower than those in group OS2 $(3.96 \pm 1.26,3.86 \pm 1.38)(P=0.000$, $0.002)$, group OS1 (3.97 $\pm 1.50,4.47 \pm 2.05)(P=0.000$, $0.000)$, and group $\mathrm{S}(5.90 \pm 1.42,6.17 \pm 1.39)(P=0.000$, 0.000). NRS-R scores in group OS1 were lower than those in group $\mathrm{S}(P=0.000,0.000)$. At $6 \mathrm{~h}$ after surgery, NRS-R scores in group $\mathrm{O}(1.79 \pm 0.78)$ were lower than those in group OS1 (4.43 \pm 1.79$)(P=0.000)$ and in group $S(6.20 \pm 1.65)$ $(P=0.000)$. At all time points $(6,12$, and $24 \mathrm{~h})$ measured, NRS-R scores in group OS2 were lower than those in group $\mathrm{OS} 1(P=0.003,0.000,0.000)$ and group $\mathrm{S}(P=0.000,0.000$, 0.000) (Figure 2A).

At all time points, NRS-S scores in group $\mathrm{O}(2.11 \pm 0.62$, $2.01 \pm 0.86,1.83 \pm 0.66)$ were lower than those in group OS2 (4.29 $\pm 2.23,3.39 \pm 1.90,4.32 \pm 1.93)(P=0.001,0.006,0.001)$, group OS1 $(5.53 \pm 1.74,4.97 \pm 1.97,5.77 \pm 1.96)(P=0.000$, $0.000,0.000)$, and group $S(7.43 \pm 1.41,6.13 \pm 1.51,6.87 \pm 1.78)$ $(P=0.000,0.000,0.000)$. NRS-S scores in group OS2 were lower than those in group OS1 $(P=0.000,0.000,0.000)$ and group $\mathrm{S}(P=0.000,0.000,0.000)$. NRS-S scores in group OS1 were lower than those in group $\mathrm{S}(P=0.000,0.000$, 0.004) (Figure 2B).

At all time points, NRS-U scores in group O (1.93 \pm 0.75 , $1.69 \pm 0.71,1.24 \pm 0.79)$ were lower than those in group OS1 $(3.30 \pm 1.34,2.93 \pm 1.60,3.33 \pm 1.24)(P=0.000,0.000,0.000)$ and group $\mathrm{S}(6.63 \pm 1.54,5.87 \pm 1.28,6.20 \pm 1.35)(P=0.000$, 


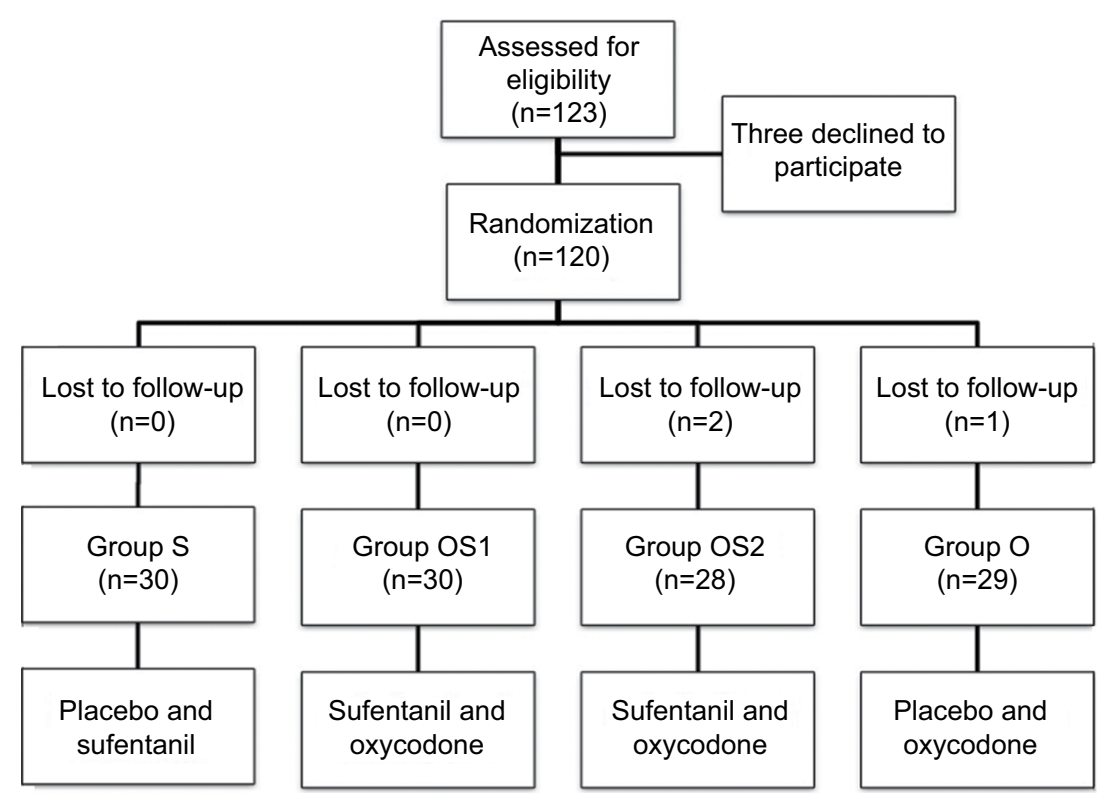

Figure I Study flow diagram.

Notes: Group S (sufentanil $100 \mu \mathrm{g}$ ), group OSI (sufentanil $70 \mu \mathrm{g}$, oxycodone $30 \mathrm{mg}$ ), group OS2 (sufentanil $50 \mu \mathrm{g}$, oxycodone $50 \mathrm{mg}$ ), and group O (oxycodone $100 \mathrm{mg}$ ). Ramosetron $0.3 \mathrm{mg}$ was added to each group.

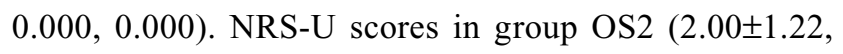
$1.64 \pm 1.37,2.39 \pm 1.26)$ were lower than those in group $\mathrm{S}(P=0.000,0.000,0.000)$. NRS-U scores in group OS1 were lower than those in group $\mathrm{S}(P=0.000,0.000,0.001)$ (Figure 2C).

At all time points, the number of PCIA boluses in group $\mathrm{O}$ was fewer than those in group OS1 and group $\mathrm{S}$. The number of PCIA boluses in group OS2 was fewer than those in group $\mathrm{S}$. Opioid consumption (sufentanil equivalents) in group $\mathrm{O}$ was lower than that in group OS1 and group S. Opioid consumption in group OS2 was lower than that in group S (Table 2).

The number of patients experiencing side effects was reported in Table 3. During the first $6 \mathrm{~h}$ after the operation, nausea was observed in five patients in group $\mathrm{S}$. The incidence was different among groups, but no significant differences were found by Bonferroni correction. No significant differences were observed in the incidences of hypotension, hypoxemia, respiratory depression, vomiting, pruritus, or dizziness among the four groups. Satisfaction scores are shown in Table 4. The distributions of 2,3 , and 5 points on the satisfaction scale varied among the groups, with significant differences found only for 3 and 5 points between group $S$ and group $\mathrm{O}$ by Bonferroni correction. The Ramsay Sedation Score was 2 in all primiparas.

\section{Discussion}

In recent years, some researchers have utilized oxycodone for postoperative analgesia. ${ }^{19,20}$ To the best of our knowledge, no previous study has compared the analgesic effects of oxycodone vs sufentanil PCIA after CS. Our study indicated that oxycodone provided better analgesia than sufentanil after cesarean delivery.

In this study, NRS-U scores in group $\mathrm{O}$ were lower than those in group OS1 and group S. NRS-U scores in group OS2 were lower than those in group S. NRS-U scores in group OS1 were lower than those in group $\mathrm{S}$ at all times

Table I Baseline demographic characteristics of patients $(n=117)$

\begin{tabular}{llllll}
\hline Parameters & Group S $(\mathbf{n}=\mathbf{3 0})$ & Group OSI $(\mathbf{n = 3 0 )}$ & Group OS2 $(\mathbf{n}=28)$ & Group O $(\mathbf{n}=\mathbf{2 9})$ & $\boldsymbol{P}$-value \\
\hline Age (years) & $31.5 \pm 3.8$ & $29.8 \pm 2.9$ & $29.8 \pm 2.6$ & $29.2 \pm 3.7$ & 0.059 \\
Height $(\mathrm{cm})$ & $161.5 \pm 4.5$ & $159.9 \pm 5.5$ & $162.3 \pm 5.2$ & $159.5 \pm 3.7$ & 0.091 \\
Weight $(\mathrm{kg})$ & $69.3 \pm 7.7$ & $68.5 \pm 7.1$ & $71.5 \pm 10.0$ & $66.2 \pm 4.8$ & 0.059 \\
BMI $\left(\mathrm{kg} / \mathrm{m}^{2}\right)$ & $26.6 \pm 2.7$ & $26.7 \pm 2.8$ & $27.0 \pm 3.3$ & $26.8 \pm 3.1$ & 0.101 \\
Gestation (weeks) & $39.2 \pm 0.9$ & $38.7 \pm 0.8$ & $39.2 \pm 0.9$ & $39.1 \pm 1.2$ & 0.262 \\
Duration of surgery (min) & $53.8 \pm 7.4$ & $51.3 \pm 4.3$ & $52.9 \pm 6.9$ & $49.7 \pm 7.6$ & 0.108 \\
\hline
\end{tabular}

Notes: Group S (sufentanil $100 \mu \mathrm{g}$ ), group OSI (sufentanil $70 \mu \mathrm{g}$, oxycodone $30 \mathrm{mg}$ ), group OS2 (sufentanil $50 \mu \mathrm{g}$, oxycodone $50 \mathrm{mg}$ ), and group O (oxycodone $100 \mathrm{mg}$ ). Ramosetron $0.3 \mathrm{mg}$ was added to each group. In all groups, the drugs were diluted to $100 \mathrm{~mL}$. Values are expressed as mean \pm SD. There was no significant difference between groups.

Abbreviation: BMI, body mass index. 
A

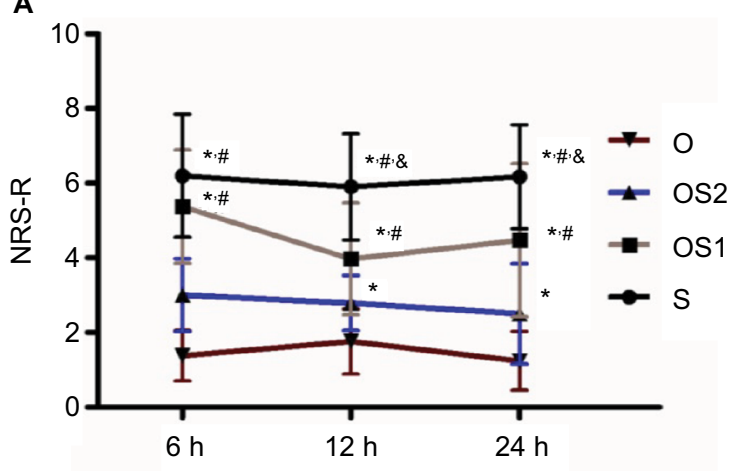

Time after surgery

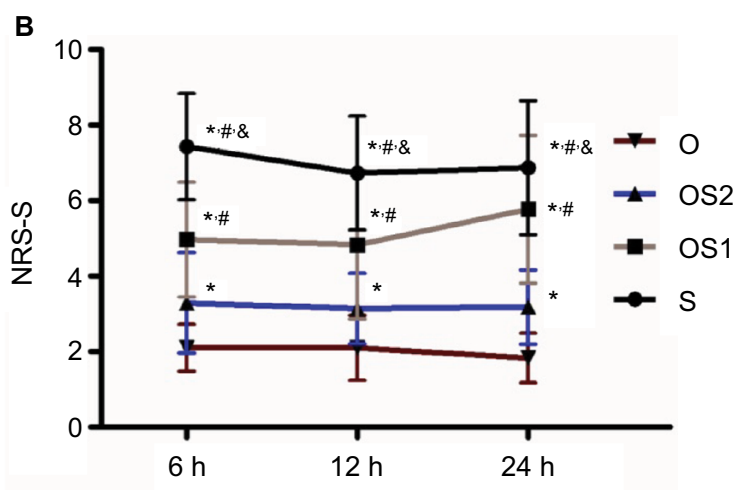

Time after surgery

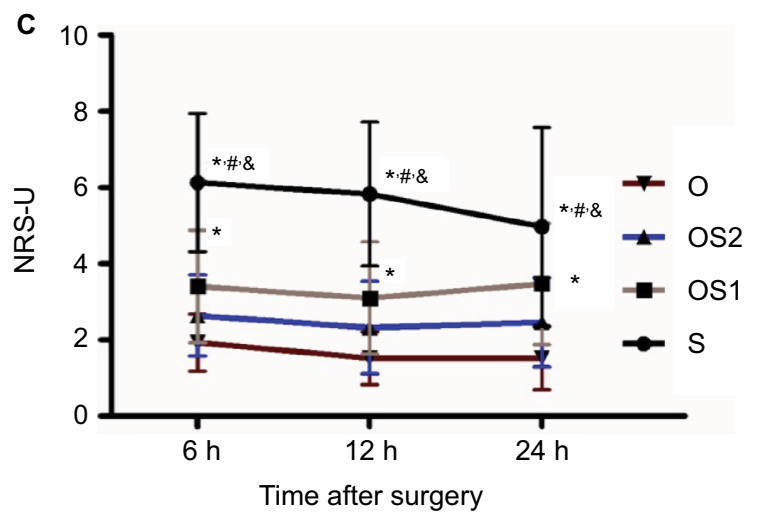

Figure 2 (A-C) The NRS-R, NRS-S, and NRS-U scores at 6, 12, and $24 \mathrm{~h}$ after the operation.

Notes: Values are presented as the mean (SD). Group $S$ (sufentanil $100 \mu$ g), group OSI (sufentanil $70 \mu g$, oxycodone $30 \mathrm{mg}$ ), group OS2 (sufentanil $50 \mu g$, oxycodone $50 \mathrm{mg}$ ), and group $\mathrm{O}$ (oxycodone $100 \mathrm{mg}$ ). Ramosetron $0.3 \mathrm{mg}$ was added to each group. In all groups, the drugs were diluted to $100 \mathrm{~mL}$. $* P<0.008 \mathrm{vs} \mathrm{group} O$; $\# P<0.008 \mathrm{vs}$ group OS2; ${ }^{\circledR} P<0.008$ vs group OSI.

Abbreviations: NRS, Numerical Rating Scale; NRS-R, NRS of incision pain at rest; NRS-S, NRS of moving into the sitting position; NRS-U, NRS of uterine cramping pain.

Table 2 Patient-controlled intravenous analgesia

\begin{tabular}{|c|c|c|c|c|c|c|c|c|c|c|c|c|}
\hline Parameters & Time points & Group S & Group OSI & Group OS2 & Group 0 & $\mathbf{P}_{1}$ & $\mathbf{P}_{2}$ & $\mathbf{P}_{3}$ & $\mathbf{P}_{4}$ & $\mathbf{P}_{5}$ & $\mathbf{P}_{6}$ & $\mathbf{P}_{0}$ \\
\hline The number of & $6 \mathrm{~h}$ & $5.4(4.2)^{*}$ & $5.0(3.7)^{*}$ & $3.2(1.4)$ & I.6 (0.5) & 0.043 & 0.000 & 0.000 & 0.020 & 0.569 & 0.004 & 0.000 \\
\hline \multirow[t]{2}{*}{ PCIA boluses } & $12 \mathrm{~h}$ & $10.9(8.8)^{*}$ & $9.0(5.5)^{*}$ & $5.7(2.6)$ & $2.9(0.8)$ & 0.049 & 0.000 & 0.000 & 0.024 & 0.162 & 0.000 & 0.000 \\
\hline & $24 \mathrm{~h}$ & $17.2(14.0)^{*}$ & I5.4 (I0.0)* & $10.5(5.5)$ & $4.8(\mathrm{I} .2)$ & 0.021 & 0.000 & 0.000 & 0.045 & 0.432 & 0.006 & 0.000 \\
\hline The amount & $6 \mathrm{~h}$ & I5.8 (6.3)* & $14.7(5.8)^{*}$ & I I.8 (2.5) & $8.7(1.3)$ & 0.010 & 0.000 & 0.000 & 0.002 & 0.363 & 0.001 & 0.000 \\
\hline of opioid & $12 \mathrm{~h}$ & $32.0(2.5)^{*}$ & $28.5(11.8)^{*}$ & $23.5(6.6)$ & $17.7(2.2)$ & 0.021 & 0.000 & 0.000 & 0.041 & 0.153 & 0.001 & 0.000 \\
\hline consumption & $24 \mathrm{~h}$ & $52.4(18.4)^{*}$ & $48.2(16.8)^{*}$ & $40.9(9.7)$ & $33.0(2.6)$ & 0.029 & 0.000 & 0.000 & 0.043 & 0.233 & 0.002 & 0.000 \\
\hline
\end{tabular}

Notes: Group S (sufentanil $100 \mu g$ ), group OSI (sufentanil $70 \mu g$, oxycodone $30 \mathrm{mg}$ ), group OS2 (sufentanil $50 \mu$, oxycodone $50 \mathrm{mg}$ ), and group $\mathrm{O}$ (oxycodone $100 \mathrm{mg}$ ). Ramosetron $0.3 \mathrm{mg}$ was added to each group. In all groups, the drugs were diluted to $100 \mathrm{~mL}$. Values are expressed as mean $\pm S D$. $* P<0.05$. $P_{1}$, group $O$ vs group OS2; $P_{2}$, group $\mathrm{O}$ vs group OSI; $\mathrm{P}_{3}$, group $\mathrm{O}$ vs group $\mathrm{S} ; \mathrm{P}_{4}$, group OSI vs group OS2; $\mathrm{P}_{5}$, group $\mathrm{S}$ vs group OSI; $\mathrm{P}_{6}$, group $\mathrm{S}$ vs group OS2; $\mathrm{P}_{0}$, comparing groups.

Abbreviation: PCIA, patient-controlled intravenous analgesia.

Table 3 Incidence of side effects n (\%)

\begin{tabular}{|c|c|c|c|c|c|}
\hline Side effects & Group $S(n=30)$ & Group OSI $(n=30)$ & Group OS2 (n=28) & Group $O(n=29)$ & $P$-value \\
\hline Hypotension & $0(0)$ & $0(0)$ & $0(0)$ & $0(0)$ & \\
\hline Hypoxemia & $0(0)$ & $0(0)$ & $0(0)$ & $0(0)$ & \\
\hline Respiratory depression & $0(0)$ & $0(0)$ & $0(0)$ & $0(0)$ & \\
\hline Nausea $(0-24$ h) & $5(16.7)^{*}$ & $0(0)$ & $0(0)$ & 0 & 0.002 \\
\hline Vomiting & $0(0)$ & $0(0)$ & $0(0)$ & 0 & \\
\hline Pruritus & $0(0)$ & $0(0)$ & $0(0)$ & 0 & \\
\hline Dizziness & $0(0)$ & I (3.3) & I (3.3) & $3(10.3)$ & 0.256 \\
\hline
\end{tabular}

Notes: Group S (sufentanil $100 \mu \mathrm{g}$ ), group OSI (sufentanil $70 \mu \mathrm{g}$, oxycodone $30 \mathrm{mg}$ ), group OS2 (sufentanil $50 \mu \mathrm{g}$, oxycodone $50 \mathrm{mg}$ ), and group O (oxycodone $100 \mathrm{mg}$ ). Ramosetron $0.3 \mathrm{mg}$ was added to each group. In all groups, the drugs were diluted to $100 \mathrm{~mL}$. All of the cases of nausea occurred within $6 \mathrm{~h}$. Values are presented as the number of patients (\%). $* P<0.05$ comparing groups. 
Table 4 Satisfaction scales on pain management at $48 \mathrm{~h}$

\begin{tabular}{llllll}
\hline Satisfaction & $\begin{array}{l}\text { Group S } \\
(\mathbf{n = 3 0 )}\end{array}$ & $\begin{array}{l}\text { Group OSI } \\
(\mathbf{n = 3 0 )}\end{array}$ & $\begin{array}{l}\text { Group OS2 } \\
(\mathbf{n = 2 8 )}\end{array}$ & $\begin{array}{l}\text { Group O } \\
\mathbf{( n = 2 9 )}\end{array}$ \\
\hline 1 & $1(3.3)$ & $0(0)$ & $0(0)$ & $0(0)$ & 0.403 \\
2 & $5(16.7)$ & $3(10.0)$ & $0(0)$ & $0(0)$ & 0.027 \\
3 & $11(36.7)$ & $10(33.3)$ & $5(17.9)$ & $2(6.9)$ & $0.025^{*}$ \\
4 & $8(26.7)$ & $11(36.7)$ & $14(50.0)$ & $12(41.4)$ & 0.323 \\
5 & $5(16.7)$ & $6(16.7)$ & $9(32.1)$ & $15(51.7)$ & $0.014 *$ \\
\hline
\end{tabular}

Notes: Satisfaction according to the following scale: I = very unsatisfactory; 2 = unsatisfactory; 3 = neutral; 4 = satisfactory; 5 = very satisfactory. Group $S$ (sufentanil $100 \mu \mathrm{g}$ ), group OSI (sufentanil $70 \mu \mathrm{g}$, oxycodone $30 \mathrm{mg}$ ), group OS2 (sufentanil $50 \mu$ g, oxycodone $50 \mathrm{mg}$ ), and group O (oxycodone $100 \mathrm{mg}$ ). Ramosetron $0.3 \mathrm{mg}$ was added to each group. In all groups, the drugs were diluted to $100 \mathrm{~mL}$. Values are presented as the number of patients (\%). ${ }^{*}<<0.05$ comparing groups.

points. Our results indicated that oxycodone was more effective than sufentanil in terms of uterine contraction pain, possibly because of oxycodone's K-opioid receptor agonist properties, ${ }^{21,22}$ suggesting the potentially superior analgesic efficacy of oxycodone in visceral pain and less side effects. Oxycodone was also more effective for incision pain. At most time points, NRS-R scores in group $\mathrm{O}$ were lower than those in the other groups. At all time points, NRS-S scores in group $\mathrm{O}$ were lower than those in the other groups.

In our study, the number of PCIA boluses in group $\mathrm{O}$ was fewer than those in group OS1 and group S. Additionally, opioid consumption was lower in group $\mathrm{O}$ than in group OS1 and group $\mathrm{S}$ at 6,12 , and $24 \mathrm{~h}$ after CS, implying that the analgesic effect in group $\mathrm{O}$ was the best. Accordingly, the patients in group OS2 received a lower overall dose than the patients in group $\mathrm{S}$. Kalso et $\mathrm{a}^{23}$ suggested that parenteral oxycodone provided fast and long-lasting pain relief compared to morphine. Therefore, we speculated that the longer duration of action of oxycodone compared to sufentanil mitigated PCIA consumption of opioids.

Hwang et $a{ }^{15}$ found that the incidence of nausea at 6-24 $\mathrm{h}$ after surgery in the oxycodone group was higher than that in the fentanyl group, but the cumulative PCIA dose in the oxycodone group was lower than that in the fentanyl group. In our study, five patients in group $\mathrm{S}$ experienced nausea and no patients in the other groups experienced nausea and vomiting. We attributed this finding to the weaker $\mu$-receptor affinity of oxycodone compared with sufentanil, which reduced nausea caused by $\mu$-receptor agonism.

Baka et $\mathrm{al}^{24}$ found that morphine concentrations in breast milk were very small in nursing mothers receiving IV morphine via PCA after cesarean delivery. Neonatal uptake does not seem to be significant. Therefore, mothers receiving routine doses of morphine via PCA after cesarean delivery should be allowed to breastfeed. In Suzette's study, ${ }^{25}$ the use of oral oxycodone ( $\leq 90 \mathrm{mg}$ in $24 \mathrm{~h}$ ) for analgesia after CS for up to 3 days postpartum posed only a minimal risk to neonates. Based on the equivalency of $2 \mathrm{mg}$ of oral oxycodone to $1 \mathrm{mg}$ of parenteral oxycodone, the safe amount of intravenous oxycodone was $45 \mathrm{mg}$ in a 24-h period. In our study, no primiparas consumed $45 \mathrm{mg}$ of oxycodone via PCIA. We demonstrated that the time to postoperative lactation initiation was $55-56 \mathrm{~h} .{ }^{26}$ The oxycodone and sufentanil infusion ended $24 \mathrm{~h}$ after surgery in our study. Based on the clearance rate of $0.7-0.8 \mathrm{~L} /$ min and the elimination half-life $\left(\mathrm{t}_{1 / 2}\right)$ of oxycodone $2-3$ $\mathrm{h}$ after intravenous administration, ${ }^{13}$ the concentration of oxycodone in breast milk in our study would probably be extremely low. In this research, neonatal feeding with breast milk was normal, unlike conditions such as pathological jaundice. Therefore, we believe that the dose of oxycodone in our protocol is safe relative to breastfeeding.

There are some limitations in this study. First, our results could only be applied to primiparas undergoing elective CS. Second, the study was not powered for the safety of primiparas and neonates. For example, although dizziness was observed in three patients in group $\mathrm{O}$, there were no significant differences in the incidence of dizziness among the four groups. Further studies with larger samples are required to investigate safety.

In summary, oxycodone PCIA may be more effective for pain relief compared to sufentanil PCIA after CS, but the incidence of side effects needs to be investigated in the future.

\section{Acknowledgment}

This study was funded by the Youth Foundation of Shanghai Municipal Health Bureau (201344196).

\section{Disclosure}

The authors report no conflicts of interest in this work.

\section{References}

1. Adeniji AO, Atanda OO. Randomized comparison of effectiveness of unimodal opioid analgesia with multimodal analgesia in post-cesarean section pain management. J Pain Res. 2013;6:419-424. 
2. Scott JC, Cooke JE, Stanski DR. Electroencephalographic quantitation of opioid effect: comparative pharmacodynamics of fentanyl and sufentanil. Anesthesiology. 1991;74(1):34-42.

3. Palmer PP, Miller RD. Current and developing methods of patientcontrolled analgesia. Anesthesiol Clin. 2010;28(4):587-599.

4. Savoia G, Loreto M, Gravino E. Sufentanil: an overview of its use for acute pain management. Minerva Anesthesiol. 2001;67(9 Suppl 1):206-216.

5. Momeni M, Crucitti M, De Kock M. Patient-controlled analgesia in the management of postoperative pain. Drugs. 2006;66(18):2321-2337.

6. Crowgey TR, Dominguez JE, Peterson-Layne C, Allen TK, Muir HA Habib AS. A retrospective assessment of the incidence of respiratory depression after neuraxial morphine administration for post cesarean delivery analgesia. Anesth Analg. 2013;117(6):1368-1370.

7. Gadsden J, Hart S, Santos AC. Post-cesarean delivery analgesia. Anesth Analg. 2005;101(5 Suppl):S62-S69.

8. Peckham EM, Traynor JR. Comparison of the antinociceptive response to morphine and morphine-like compounds in male and female Sprague Dawley rats. J Pharmacol Exp Ther. 2006;316(3):1195-1201.

9. Narita M, Nakamura A, Ozaki M, et al. Comparative pharmacological profiles of morphine and oxycodone under a neuropathic pain-like state in mice: evidence for less sensitivity to morphine. Neuropsychopharmacology. 2008;33(5):1097-1112.

10. Kalso E. How different is oxycodone from morphine? Pain. 2007;132(3):227-228.

11. De Schepper HU, Cremonini F, Park MI, Camilleri M. Opioids and the gut: pharmacology and current clinical experience. Neurogastroenterol Motil. 2004;16(4):383-394.

12. Pasternak GW. Molecular biology of opioid analgesia. J Pain Symptom Manage. 2005;29(5 Suppl):S2-S9.

13. Kokki H, Kokki M, Sjövall S. Oxycodone for the treatment of postoperative pain. Expert Opin Pharmacother. 2012;13(7):1045-1058.

14. Pereira J, Lawlor P, Vigano A, Dorgan M, Bruera E. Equianalgesic dose ratios for opioids. a critical review and proposals for longterm dosing. J Pain Symptom Manage. 2001;22(2):672-687.

15. Hwang BY, Kwon JY, Kim E, Lee DW, Kim TK, Kim HK. Oxycodone vs. fentanyl patient-controlled analgesia after laparoscopic cholecystectomy. Int J Med Sci. 2014;11(7):658-662.
16. Polanin JR, Pigott TD. The use of meta-analytic statistical significance testing. Res Synth Methods. 2015;6(1):63-73.

17. Faul F, Erdfelder E, Lang AG, Buchner A. G*Power 3: a flexible statistical power analysis program for the social, behavioral, and biomedical sciences. Behav Res Methods. 2007;39(2):175-191.

18. Faul F, Erdfelder E, Lang AG, Buchner A. Statistical power analyses using $\mathrm{G}^{*}$ Power 3.1: tests for correlation and regression analyses. Behav Res Methods. 2009;41(4):1149-1160.

19. Lenz H, Sandvik L, Qvigstad E, Bjerkelund CE. Raeder J. A comparison of intravenous oxycodone and intravenous morphine in subjectcontrolled postoperative analgesia after laparoscopic hysterectomy. Anesth Analg. 2009;109(4):1279-1183.

20. Koch S, Ahlburg P, Spangsberg N, Brock B,Tønnesen E, Nikolajsen L. Oxycodone vs. fentanyl in the treatment of early post-operative pain after laparoscopic cholecystectomy: a randomized double-blind study. Acta Anaesthesiol Scand. 2008;52(6):845-850.

21. Nozaki C, Saitoh A, Tamura N, Kamei J. Antinociceptive effect of oxycodone in diabetic mice. Eur J Pharmacol. 2005;524(1-3): 75-79.

22. Nielsen CK, Ross FB, Lotfipour S, Saini KS, Edwards SR, Smith MT. Oxycodone and morphine have distinctly different pharmacological profiles: radioligand binding and behavioural studies in two rat models of neuropathic pain. Pain. 2007;132(3):289-300.

23. Kalso E, Pöyhiä R, Onnela P, Linko K, Tigerstedt I, Tammisto T. Intravenous morphine and oxycodone for pain after abdominal surgery. Acta Anaesthesiol Scand. 1991;35(7):642-646.

24. Baka NE, Bayoumeu F, Boutroy MJ, Laxenaire MC. Colostrum morphine concentrations during postecesarean intravenous patientcontrolled analgesia. Anesth Analg. 2002;94(1):184-187.

25. Seaton S, Reeves M, McLean S. Oxycodone as a component of multimodal analgesia for lactating mothers after Caesarean section: relationships between maternal plasma, breast milk and neonatal plasma levels. Aust N Z J Obstet Gynaecol. 2007;47(3):181-185.

26. NieY, Liu Y, Luo Q, Huang S. Effect of dexmedetomidine combined with sufentanil for post-caesarean section intravenous analgesia: a randomised placebo-controlled study. Eur J Anaesthesiol. 2014;31(4):197-203.
Journal of Pain Research

\section{Publish your work in this journal}

The Journal of Pain Research is an international, peer reviewed, open access, online journal that welcomes laboratory and clinical findings in the fields of pain research and the prevention and management of pain. Original research, reviews, symposium reports, hypothesis formation and commentaries are all considered for publication

\section{Dovepress}

The manuscript management system is completely online and includes a very quick and fair peer-review system, which is all easy to use. Visit http://www.dovepress.com/testimonials.php to read real quotes from published authors. 